\title{
Relevance vector machine based fault classification in wind energy conversion system
}

\author{
Rekha S. N. ${ }^{1}$, P. Aruna Jeyanthy ${ }^{2}$, D. Devaraj ${ }^{3}$ \\ ${ }^{1}$ Sapthagiri College of Engineering, India \\ ${ }^{2,3}$ Kalasalingam Academy of Research and Education (KARE), India
}

\begin{tabular}{l} 
Article Info \\
\hline Article history: \\
Received May 15, 2018 \\
Revised Dec 9, 2018 \\
Accepted Jan 2, 2019 \\
\hline Keywords: \\
Fault detection \\
Gaussian kernel \\
Relevance vector machine \\
System \\
Wind energy conversion
\end{tabular}

Wind energy conversion

\begin{abstract}
This Paper is an attempt to develop the multiclass classification in the Benchmark fault model applied on wind energy conversion system using the relevance vector machine (RVM). The RVM could apply a structural risk minimization by introducing a proper kernel for training and testing. The Gaussian Kernel is used for this purpose. The classification of sensor, process and actuators faults are observed and classified in the implementation. Training different fault condition and testing is carried out using the RVM implementation carried out using Matlab on the Wind Energy Conversion System (WECS). The training time becomes important while the training is carried out in a bigger WECS, and the hardware feasibility is prime while the testing is carried out on an online fault detection scenario. Matlab based implementation is carried out on the benchmark model for the fault detection in the WECS. The results are compared with the previously implemented fault detection technique and found to be performing better in terms of training time and hardware feasibility.
\end{abstract}

Copyright $@ 2019$ Institute of Advanced Engineering and Science. All rights reserved.

\section{Corresponding Author:}

Rekha S. N.,

Sapthagiri College of Engineering,

Bangalore, India.

Email: sn_rekha@ rediffmail.com

\section{INTRODUCTION}

The fault detection in the WECS is an important aspect in the working of the wind power generation system, as the faults occurring in the system would increase the maintenance cost. Development of the overall fault detection including the turbine, generator, converter, pitch and the drive train becomes important considering the cost involved in the maintenance of the WECS. The benchmark model wind turbine for fault identification, which includes the sensor, process and actuator fault condition, is developed [1]. A 4.8 MW WECS model is developed in order to observe the faults in the system. SVM based fault detection is carried out in Wind turbines and compared with the ANN for the accuracy, training and tuning times [2]. The linear SVM performed better in comparison with the ANN. The classification using RVM performed better than the SVM while the training time is said to be higher [3]. Wind generator bearing fault are sensed by the sound and vibration in the tower using empirical mode decomposition method [4]. A nine turbine based wind farm challenge to detect the wind turbine faults in the individual turbine are carried out [5]. A state estimation set membership approach based implementation is found in fault detection of benchmark model with noise [6]. A multi-objective optimization framework for large scale wind turbine system is developed using the $H / H$ observer to detect the sensor and actuator fault [7]. Especially fault detection is a classification between two classes; normal state or fault and for the classification, support vector machine (SVM) is a useful machine learning method [7], [8], [9] and applications to fault detections are reported [10].

This paper takes up the implementation from the benchmark model and implement the RVM on the benchmark model for the wind fault identification problem. The overall faults like the sensor, process and 
actuator faults are included in order to classify the faults according the measurement from different sensors from the WECS. Further the paper is sectioned as follows, Section-II would talk about the different sections of the WECS where the fault is detected.Section-III talks about the RVM implementation on the wind fault detection.Section-IV infers the results and discussion followed by the conclusion and the references.

\subsection{Wind energy conversion system model}

The benchmark model developed in [1] is used in the present implementation. It comprises of the wind model, blade and pitch model, drive train model, generator/converter model, controller and parameters. In the wind model the different sequence of wind is stored as a vector $v_{w}$, which would be used for the input to the wind turbine. The Blade and Pitch model comprises of the aerodynamic and the pitch model of the turbine as defined in (1).

$$
\tau_{r}(t)=\frac{\rho \pi R^{3} C_{q}(\lambda(t) \cdot \beta(t)) v_{w}(t)^{2}}{2}
$$

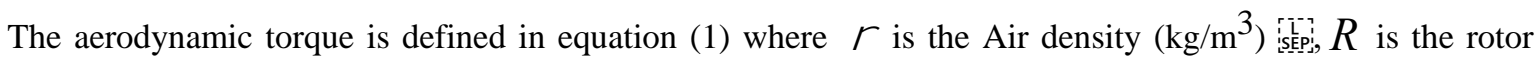
radius, $C_{q}$ rotor torque coefficient, tip speed ratio, blade pitch angle.

If the wind turbine has three blades and thus would have three blade pitch angles. Thus the torque equation would be as defined in (2), which is the sum of torques in all the three blades.

$$
\tau_{w}(t)=\sum_{1 \leq i \leq 3} \frac{\rho \pi R^{3} C_{q}\left(\lambda(t) \cdot \beta_{i}(t)\right) v_{w}(t)^{2}}{6} .
$$

The reason that value varies for each blade introduces little variation in the torque developed by each blade, though the overall behavior of the model is similar to that of the model with similar value. The hydraulic pitch system is a closed loop model defined by a second order transfer function which is a piston servo system.

$$
\frac{\beta(s)}{\beta_{c}(s)}=\frac{\omega_{n}^{2}}{s^{2}+2 \varsigma \omega_{n} s+\omega_{n}^{2}}
$$

Equation (3) defines the second order transfer function of hydraulic pitch system where is the damping factor, natural frequency defined by $\quad n$. The transfer function is defined for all three-pitch system in similar way. The damping factor is the same for all the three-pitch system if there are no disturbances. Hydraulic power drop and the increase in air pressure is are the parameters that vary when there is a fault occurrence in the pitch system. The parameters for power drop is defined as $\omega_{n 2}$ and $\varsigma_{2}$ and that of the air pressure is $\omega_{n 3}$ and $\varsigma_{3}$. The closed loop pitch actuator being the linear system with change in sensor gain affecting it would need mean of two sensor values to be fed to the actuator. Thus the pitch reference would be changed according to the changes sensor values which is indicated as follows.

$$
\beta_{r, f, i}[n]=\beta_{r, i}[n]-\frac{\Delta \beta_{i, m 1}[n]+\Delta \beta_{i, m 2}[n]}{2}
$$

Where $i \in\{1,2,3\}$ and $\beta_{r, f, i}[n]$ is the reference pitch that gets generated after the disturbance. The model of transferring the torque from rotor to the generator is defined as the drive train model. A gear box in the middle to convert the lower speed to the higher speed is represented as a two mass model defined in (5) and (6).

$$
J_{r} \omega_{r}(t)=\tau_{r}(t)-K_{d t} \theta_{\Delta}(t)-\left(B_{d t}+B_{r}\right) \omega_{r}(t)+\frac{B_{d t}}{N_{g}} \omega_{g}(t)
$$




$$
\begin{aligned}
& J_{g} \dot{\omega}_{g}(t)=\frac{\eta_{d t} K_{d t}}{N_{g}} \theta_{\Delta}(t)+\frac{\eta_{d t} B_{d t}}{N_{g}} w_{\mathrm{r}}(t)-\left(\frac{\eta_{d t B_{d t}}}{N_{g}^{2}}+B_{g}\right) \omega_{g}(t)-\tau_{g}(t) \\
& \dot{\theta}_{\Delta}(t)=\omega_{r}(t)-\frac{1}{N_{g}} \omega_{g}(t)
\end{aligned}
$$

Where $J_{r}$ the moment of inertia of low speed shaft is, $K_{d t}$ is the torsion stiffness of the drive train, $B_{d t}$ is the torsion damping coefficient of the drive train, $B_{g}$ is the viscous friction of the high speed shaft. $N_{g}$ is the gear ratio, $J_{g}$ is the moment of inertia of the high speed shaft. $\eta_{d t}$ is the efficiency of the drive train. $\theta_{\Delta}(t)$ is the torsion angle of the drive train. The fault in the drive train is due to variation in the drive train efficiency which would be denoted by $\eta_{d t 2}$ instead of $\eta_{d t}$.

The electrical model which comprises of the generator and the converter which works in frequency which is much higher than the benchmark model is defined by the first order transfer function as defined in (7).

$$
\frac{\tau_{g}(s)}{\tau_{g, r}(s)}=\frac{\alpha_{g c}}{s+\alpha_{g c}}
$$

Where $\alpha_{g c}$ is the generator and converter parameter. The generator power is defined by (8)

$$
P_{g}(t)=\eta_{g} \omega_{g}(t) \tau_{g}(t)
$$

where $\eta_{g}$ is the efficiency of the generator. The control scheme chosen for this implementation simple as the focus is on the fault detection of WECS. In order to simplify the benchmark model the drive train damper is avoided. There are two modes in which this implementation would work, one is the power optimization mode and the reference power mode. The power optimization mode is when the speed of the wind is greater than the nominal speed. The controller starts when there is less power generated from the wind energy due to wind speed less than the nominal speed. It is denoted as

$$
P_{g}[n] \geq P_{r}[n] \bigvee \omega_{g}[n] \geq \omega_{\text {nom }}
$$

where $\omega_{\text {nom }}$ is the nominal generator speed and the mode changes from this mode 2 to the mode 1 if

$$
\omega_{g}[n] \leq \omega_{\text {nom }}-\omega_{\Delta}
$$

where $\omega_{\Delta}$ is the offset that is subtracted from the nominal speed to avoid the change from mode 1 to mode 2 and vice versa frequently. The conditions of fault and the mode variation along with the model parameters are used as it is from [1].

\section{RELEVANCE VECTOR MACHINE BASED IMPLEMENTATION OF FAULT DETECTION}

\begin{tabular}{|c|c|c|c|}
\hline Fault No. & Fault Type & Fault Site & Symbols \\
\hline $1 \mathrm{a}$ & Fixed Value & \multirow[t]{3}{*}{ Sensor Faults Blade Positions } & $\Delta \beta_{1, m 1,} \Delta \beta_{i 1 m 2}$ \\
\hline $1 b$ & Gain Factor & & $\Delta \beta_{2, m 1}, \Delta \beta_{2, m 2}$ \\
\hline & & & $\Delta \beta_{3, m 1}, \Delta \beta_{3, m 2}$ \\
\hline $2 \mathrm{a}$ & Fixed Value & \multirow[t]{2}{*}{ Sensor Fault Rotor Speed } & \multirow[t]{2}{*}{$\Delta \omega_{r, m 1} \Delta \omega_{r, m 2}$} \\
\hline $2 b$ & Gain Factor & & \\
\hline $3 \mathrm{a}$ & Fixed Value & \multirow[t]{2}{*}{ Sensor Fault Generator Speed } & \multirow[t]{2}{*}{$\Delta \omega_{g, m 1} \Delta \omega_{g, m 2}$} \\
\hline $3 b$ & Gain Factor & & \\
\hline $4 \mathrm{a}$ & Offset & Actuator Fault converter system & \multirow{3}{*}{$\begin{array}{c}\Delta \tau_{g} \\
\Delta \beta_{1, \Delta} \Delta \beta_{2,} \Delta \beta_{3}\end{array}$} \\
\hline $5 \mathrm{a}$ & Abrupt Changed Dynamics & Actuator Fault & \\
\hline $5 b$ & Slow Changed Dynamics & Pitch Systems & \\
\hline 6 & Changed Dynamics & System Fault Drive Train & $\Delta \omega_{r}, \Delta \omega_{g}$ \\
\hline
\end{tabular}

The different fault conditions are trained on the Relevance Vector Machine (RVM) and a multi class RVM structure is developed in order to test the different fault condition of the wind fault that is considered in [1]. The multiple RVM structures are developed as discussed in [11]. The different fault conditions are as given in the Table 1 is introduced for training the RVM and testing it.

Table 1.Different Fault Conditions Trained Using RVM 
The pitch positions are considered for the implementation of the $1 \mathrm{a}$ and $1 \mathrm{~b}$ faults that would be taken as the vector for the RVM training. The vector that reflects the sensor faults in blade positions is as given in the following

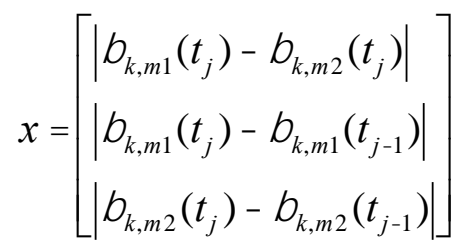

Where $\mathrm{k}=1,2,3$ which is the denoting blade number and $\mathrm{i}=1,2$ denotes the mode in which the WECS is working. And $t_{j}$ and $t_{j 1}$ are the time instant at $\mathrm{j}$ and $\mathrm{j}-1$ respectively. The absolute value of ${ }_{k, m 1}\left(t_{j}\right) \quad{ }_{k, m 2}\left(t_{j}\right) \mid$ would vary between .001 and 2 , but in order to differentiate from the fault and the normal scenario the value is predefined as 5000 . The parameters for the faults defined by $2 \mathrm{a}, 2 \mathrm{~b}, 3 \mathrm{a}$ and $3 \mathrm{~b}$ $\omega_{g, m i}, \omega_{g, m i}$ are used for training. The vector for training is given by the following.

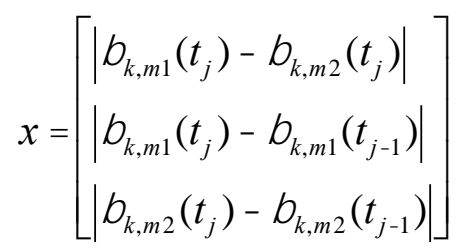

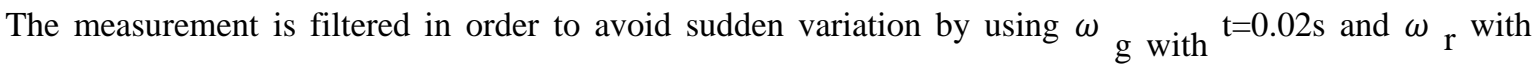
$\mathrm{t}=0.06 \mathrm{~s}$. In order to increase the ability to measure distinctly the Gaussian variance is increased to 15 while measuring. For faults $4 \mathrm{a}$ and 6 the vector is as defined in the following,

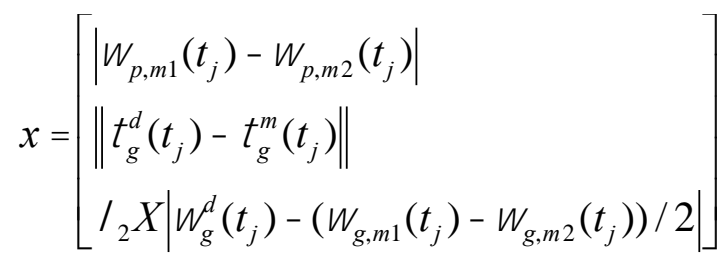

where $\quad \begin{aligned} & d \\ & g\end{aligned}$ is the desired generator speed, $\begin{gathered}d \\ g\end{gathered}$ is the desired generator torque given by the controller ( $\frac{P_{r}}{d}$ where $P_{r}$ is the power which is desired to be produced). The factor ${ }_{2}=10{ }^{6} X{ }_{\text {wind }}^{6}$ is used in the $g$

third component of $\mathrm{x}$ in order to utilize the wind speed and for normalization.

Relevance vector Machine for Fault Detection in Wind Turbines:

RVM is used to develop ten separate training models for different fault conditions. For ten different faults ten different regression functions is articulated. The regression function is used to map the input to different regions of the state space. The function that is used for the regression function is given as below,

$$
f_{r v m}(x)=\sum_{i=1}^{N} \alpha_{i} K\left(x, x_{i}\right)+b
$$

where $K(.,$.$) is the Gaussian kernel function , x_{i}, i=1 \ldots N$, are the training samples which comprise of all the fault condition and non fault condition values of the 11 variable from all the three blades. The sparse parameter $\alpha_{i}$ is determined using the Bayesian estimation algorithm. The regression is carried out using the logistic regression as given by

$$
(d=1 \mid x)=\frac{1}{1+\exp \left(-f_{r v m}(x)\right.}
$$


The mapping function is generated for each of this implementation by applying the regression algorithm explained in [12]. The RVM is trained for each fault situation and the trained model is generated after the regression procedure. The parameter is optimized by maximizing the objective function

$$
J(\alpha)=\sum_{i=1}^{N} \log p\left(d_{i} \mid x_{i}\right)+\sum_{i=1}^{N} \log p\left(\alpha_{i} \mid \lambda_{i}^{*}\right)
$$

Where $\lambda_{i}^{*}$ is the maximum a posteriori estimate of hyperparameter $\lambda_{i}$. The input $\mathrm{x}$ for all the fault condition are defined in the previous section and the RVM training is carried out by the use of the RVM implementation thus introduced in the above .

\section{RESULTS AND DISCUSSIONS}

The Matlab based Implementation is carried out and the results are as shown in the following discussion. The third fault scenario as discussed in [1] is applied for the implementation which is the rotor speed sensor fault occurring in the two blades of the turbine. While carrying out the training process the time taken for the training process is calculated for making all the nine faults trained and the models to be developed for each fault.

The model created after the training process comprises of the $\alpha$,the sparse parameter, and the bias value $b$ along with the kernel structure. The amount of memory space needed for storing it would be a parameter for the hardware feasibility of the proposed method. The memory space required for it be stored is around $160 \mathrm{~kb}$ of the memory thus allowing it to be feasible in hardware implementation. By giving the different wind speed, which is randomly generation. Due to the variation in the wind the torque generated in the Figure 1.

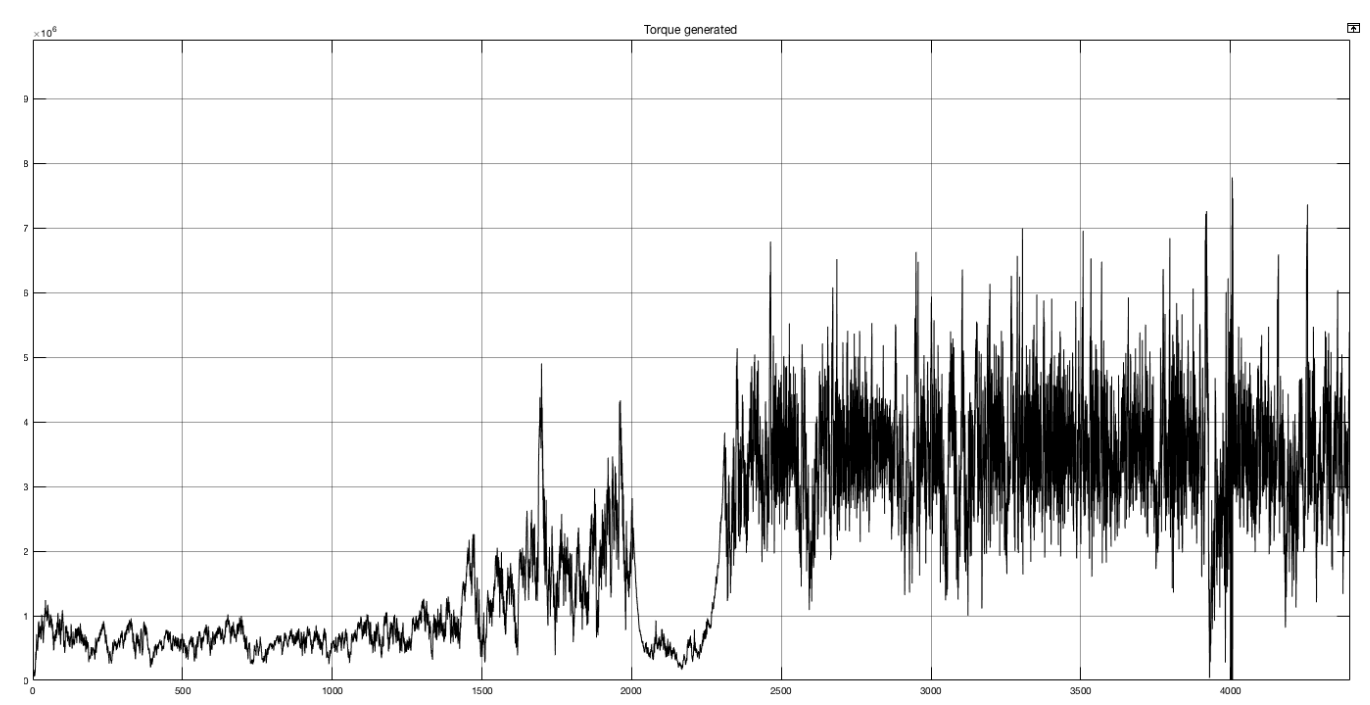

Figure 1. Torque Waveform with random wind supply Turbine

The simulation is run for 4400 Secs. The faults are applied at different places like the below.

1. Fault type $1 \mathrm{a}, \mathrm{b}_{1, \mathrm{~m} 1}=-3^{\circ}$ occurring between $100 \mathrm{~s}$ and $200 \mathrm{~s}$.

2. Fault type $1 \mathrm{~b}, \mathrm{~b}_{2, \mathrm{~m} 2}=5^{\circ} 2, \mathrm{~m} 2$ on $500-600 \mathrm{~s}$.

3. Fault type $1 \mathrm{a}, \mathrm{b}_{3, \mathrm{~m} 1}=7^{\circ}$ on $900-1000 \mathrm{~s}$.

4. Fault type $2 \mathrm{a}, \mathrm{w}_{\mathrm{r}, \mathrm{m} 1}=2 \mathrm{rad} . \mathrm{s}^{-1}$ on $1200-1300 \mathrm{~s}$.

5. Faults type $2 \mathrm{~b}$ and $3 \mathrm{~b}, \mathrm{w}_{\mathrm{r}, \mathrm{m} 2}=0.5 \mathrm{w}_{\mathrm{r}, \mathrm{m} 2}$ and $\mathrm{w}_{\mathrm{g}, \mathrm{m} 1}=1.5 \mathrm{w}_{\mathrm{g}, \mathrm{m} 1}$ on $1700-1800 \mathrm{~s}$.

6. Fault type $4 \mathrm{a}, \mathrm{t}_{\mathrm{g}}=\mathrm{t}_{\mathrm{g}}-1000 \mathrm{Nm}$ on $4200-4300 \mathrm{~s}$. 
7. Fault type $6, \mathrm{~h}_{\mathrm{dt}}=0.22 \mathrm{~h}_{\mathrm{dt}}$

8. Fault type 5a, parameters in pitch actuator $2\left(\mathrm{w}_{\mathrm{n}}, \mathrm{z}\right){ }_{8}$ abruptly changed from $[11.11,0.6]$ to $[5.73,0.45]$ from 3200 and 3300s.

9. Fault type $5 b$, parameters in pitch actuator $3\left(\mathrm{w}_{\mathrm{n}}, \mathrm{z}\right)$ changed slowly (with a linear function) from [11.11, $0.6]$ to $[3.42,0.9]$ over $30 \mathrm{~s}$, remained constant during 40s, and then decreased again over 30s from 3400 and 3500 s.

While carrying out the training process the time taken for training all the fault and the non fault condition for all the nine fault conditions by using RVM is given in Table 2. After training the faults in the RVM implementation. The fault detection is tested with the above faults using the models developed using RVM.

The detection of fault would show the 1 in the detection graph and zero in the detection graph when there is no fault. Figures 1 and 2 displays the wind turbine torque and the wind speed respectively in Turbine. Figures 3 and 4 displays the fault detected in Blade 1 and Blade 2 1200-1300s and 1700-1800s. The hardware feasibility of the proposed algorithm would require the time taken for the training portion and the memory space needed to store the models developed after the training process. The Table 2 displays the time taken for all the nine faults trained and the model generation for all the faults and the space for the models stored in the memory. The table is developed considering the i5 processor, $3.2 \mathrm{GHz}$ processor with the $8 \mathrm{~GB}$ ram.

Table 2. Time taken for Training Each Faults Using RVM and Memory Used for the Model Thus Developed

\begin{tabular}{|c|c|c|c|c|}
\hline Fault No. & Fault Type & Fault Site & Memory Space for model & Execution Time \\
\hline $1 \mathrm{a}$ & Fixed Value & \multirow[t]{2}{*}{ Sensor Faults Blade Positions } & \multirow[t]{2}{*}{$16 \mathrm{~KB}$} & 1054 secs on an average for \\
\hline $1 b$ & Gain Factor & & & each model \\
\hline $2 \mathrm{a}$ & Fixed Value & \multirow[t]{2}{*}{ Sensor Fault Rotor Speed } & \multirow[t]{2}{*}{$20 \mathrm{~KB}$} & \\
\hline $2 b$ & Gain Factor & & & \\
\hline $3 a$ & Fixed Value & \multirow[t]{2}{*}{ Sensor Fault Generator Speed } & \multirow[t]{2}{*}{$10 \mathrm{~KB}$} & \\
\hline $3 b$ & Gain Factor & & & \\
\hline $4 \mathrm{a}$ & Offset & Actuator Fault converter system & $1 \mathrm{~KB}$ & \\
\hline \multirow[t]{2}{*}{$5 a$} & Abrupt & Actuator Fault & \multirow[t]{5}{*}{$16 \mathrm{~KB}$} & \\
\hline & $\begin{array}{l}\text { Changed } \\
\text { Dynamics }\end{array}$ & Pitch Systems & & \\
\hline \multirow[t]{3}{*}{$5 b$} & Slow & & & \\
\hline & Changed & & & \\
\hline & Dynamics & & & \\
\hline \multirow[t]{2}{*}{6} & Changed & System Fault Drive Train & \multirow[t]{2}{*}{$47 \mathrm{~KB}$} & \\
\hline & Dynamics & & & \\
\hline
\end{tabular}

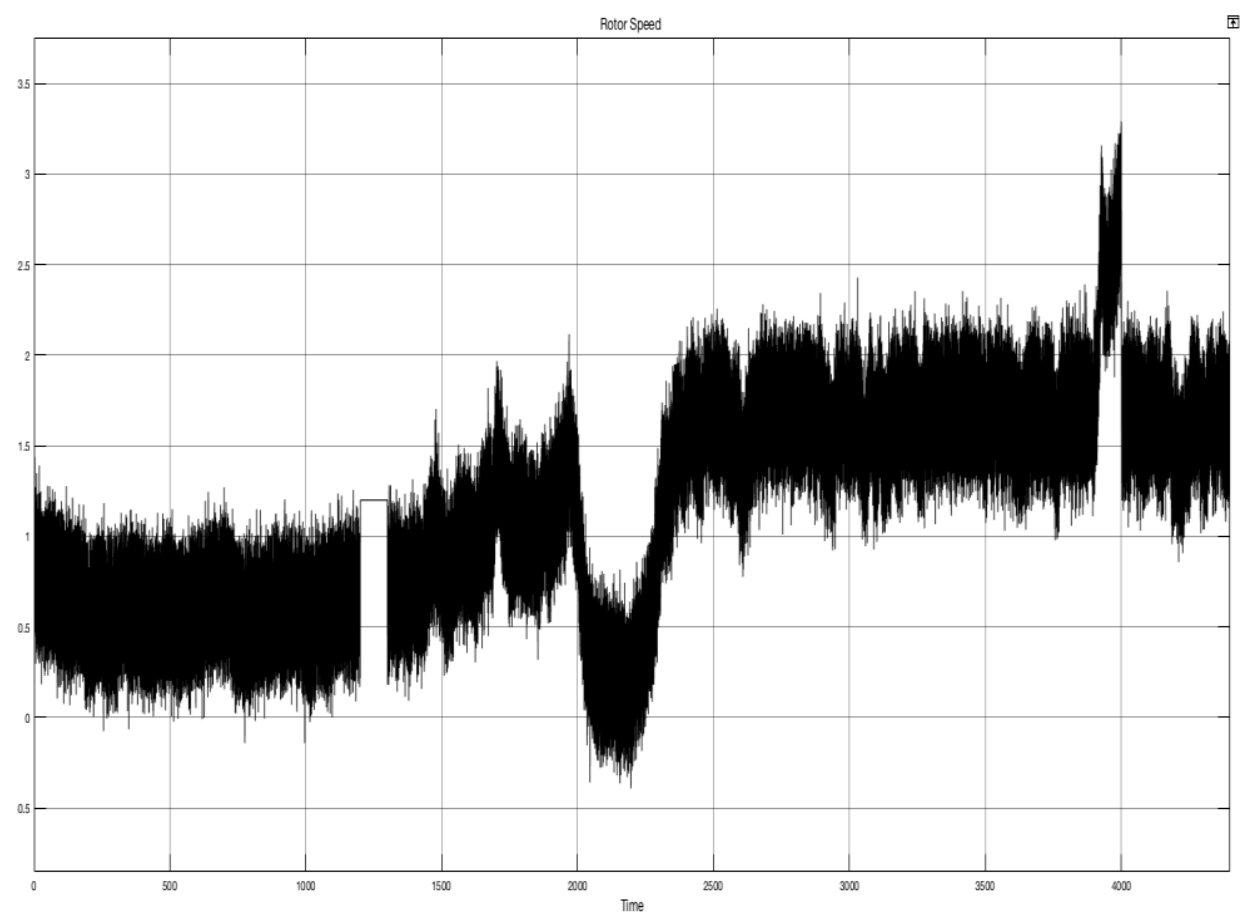

Figure 2. Speed in wind turbine 


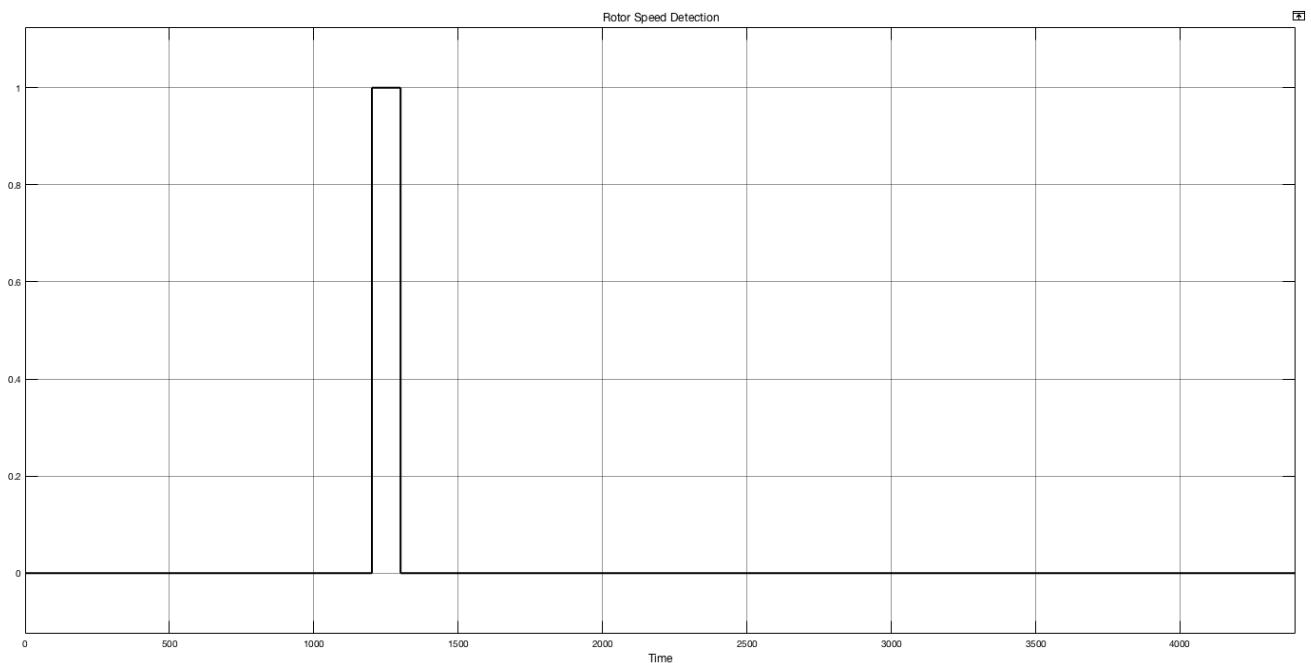

Figure 3. Rotor speed fault detected in blade 1

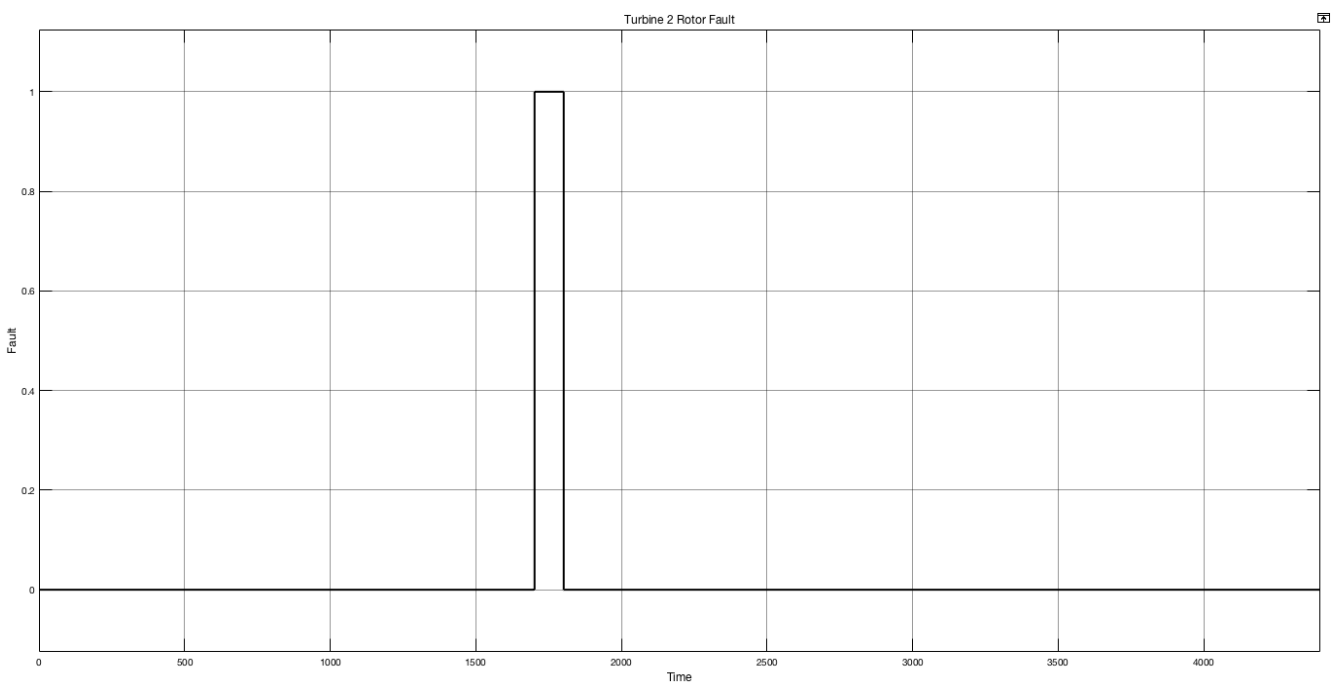

Figure 4. Rotor speed fault detected in blade 2

\section{CONCLUSION}

The Relevance Vector Machine based implementation was carried out with the benchmark model developed as mentioned in the literature. The RVM function was trained and ten different models were developed for each kind of fault and the results were found to be satisfactory. The hardware feasibility study takes in to consideration the execution time and the memory usage for the models thus developed while training. The amount of execution time and the memory used clearly supports the hardware feasibility positively.

\section{REFERENCES}

[1] Odgaard, P.F., Stoustrup, J., and Kinnaert, M. "Fault tolerant control of wind turbines- a benchmark model," IEEE Transactions on Control Systems Technology, Vol: 21, No.4, 1168 - 1182, July 2013.

[2] Santos, P, Villa, L.F, Reñones, A., Bustillo, A, Maudes, J, “An SVM-Based Solution for Fault Detection in Wind Turbines," Sensors, 15, 5627-5648, 2015.

[3] Muhammad Rafi, Mohammad Shahid Shaikh, "A comparison of SVM and RVM for Document Classification," ICoCSIM, Medan Indonesia, 2012.

[4] Mollasalehi, E, Wood, D, Sun, Q. "Indicative Fault Diagnosis of Wind Turbine Generator Bearings Using Tower Sound and Vibration," Energies, 10, 1853, 2017. 
[5] Anders BechBorcehrsen, JesperAbildgaardLarsen, JakobStoustrup, "Fault Detection and Load Distribution for the Wind Farm Challenge," IFAC Proceedings Volumes, Volume 47, Issue 3, Pages 4316-4321, 2014.

[6] Seyed Mojtaba Tabatabaeipour and Peter F. Odgaard, and Thomas Bak, "Fault detection of a benchmark wind turbine using interval analysis," American Control Conference Fairmont Queen Elizabeth, Montréal, Canada June 27-June 29, 2012.

[7] Xiukun Weiand LihuaLiu, "Fault detection of large scale wind turbine systems," International Conference on Computer Science and Education (ICCSE), IEEE, 2010.

[8] Najim Aldin Mohsun, "Broken rotor bar fault classification for induction motor based on support vector machineSVM," Engineering \& MIS (ICEMIS), 2017 International Conference on, February 2018.

[9] Qian Zhao et al, "Damage detection of wind turbine blade based on wavelet analysis," Image and Signal Processing (CISP), 2015 8th International Congress on 14-16, IEEE, Oct 2015.

[10] Mohanty, Soumya R., et al. "Comparative study of advanced signal processing techniques for islanding detection in a hybrid distributed generation system," IEEE Transactions on Sustainable Energy 6, 122-131, 12015.

[11] Thayananthan A., Navaratnam R., Stenger B., Torr P.H.S., Cipolla R. "Multivariate Relevance Vector Machines for Tracking. In: Leonardis A., Bischof H., Pinz A. (eds) Computer Vision-ECCV 2006," Lecture Notes in Computer Science, vol 3953, Springer, Berlin, Heidelberg, ECCV 2006.

[12] Liyang Wei and Robert M. Nishikawa, "Relevance Vector Machine Learning for Detection of Microcalcifications in Mammograms," IEEE, 2005. 